\title{
A CONCEPTION OF THE E-BUSINESS RECEPTION MODEL (EBRM)
}

\author{
Zbigniew Pastuszak, Maria Curie-Sklodowska Univeristy, Poland, z.pastuszak@umcs.lublin.pl
}

\begin{abstract}
The reception of e-business solutions is one of the key issues for enterprises that operate in the new economy environment. This article presents a conception (an "exploratory" study) of the $e$ business reception model and fundamental research hypotheses for its verification. They are at the core of research scheduled for implementation in selected European countries in 2009.
\end{abstract}

Keywords: e-Business, Reception, Model, Net Readiness, TAM, TTF, Information Technology

\section{INTRODUCTION}

Knowledge of various factors (technical, organisational, etc.) that determine the reception of ebusiness in enterprises is a prerequisite to sustaining and further developing their competitive position. With new economy well in place, this position rests in the main on global competition and the speed of implementing and commercialising technological innovation, particularly associated with Information Systems-Information Technology or IS/IT for short [24]. A broad range of aspects of IS/IT implementations and the results obtained have given rise to a barrage of publications including but not limited to [1], [6], [8], [9], [12], [13], [16], [19], [21], [23], [28], [29], [33], [34], [36], and [39]. These processes are also reflected in the myriad of methods and ranking lists aiming to measure the level of development of individual economies in the area of e-business and information society. Pioneering studies of E. Garfield [14], T.W. Schultz [35] and F. Machlup [27] as well as more recent studies carried out by The Economist [41], Harvard University [18], OECD (Organization for Economic Co-operation and Development) and the World Bank [42], World Economic Forum [43], ABS (Australian Bureau of Statistics) [3] and [4] or APEC (AsiaPacific Economic Cooperation) [2] are but a few pertinent examples.

An in-depth analysis of these studies leads to the conclusion that besides the accessibility of the technological infrastructure, competitiveness of individual countries (on a macro-economic level) rests, in no small measure, on the development of skills that allow the administrators of this infrastructure to use it accordingly and on broad implementation of IS/IT solutions in economy (on a micro-economic level) in order to reduce transaction costs and increase effectiveness.

\section{E-BUSINESS RECEPTION DETERMINANTS}

Capitalising on the studies mentioned above and on the basic new economy rankings lists, it is possible to establish a general classification of e-business reception determining factors. These factors can be classified under two groups, defined later in this article as external and internal factors of e-business reception.

As the name denotes, external (exogenic) factors reflect external conditions of enterprise functioning in a given country. The effect of these factors and the level of economic development in the pertinent area indicate how far a given country is behind relative to world leaders, i.e. the e-technological gap in economy [32]. The following factors fall under the terms of reference of this group:

- innovations,

- domestic information technology infrastructure,

- general economic factors,

- human resources.

Internal (endogenic) factors, on the other hand, indicate the readiness of the enterprise to adopt ebusiness internally. Their interrelations determine, in effect, the competitive position of the enterprise against the background of subjective macro-scale conditions resulting from the economic development of the country where the enterprise operates. The discrepancy between the level of enterprise readiness to adopt e-business and the level achieved by rival companies is defined in this article as the eorganisational gap. Endogenic factors includes the following:

- strategic factors of e-business reception which define the specific character of a given company, and its subjective features relating to e-business reception [17], i.e. leadership, management, competences and IT infrastructure,

- environment and process-related factors of ebusiness reception which determine individual, organisational and technological characteristics of a given enterprise, i.e. strategy and structure, support systems, user characteristics, and the manner of generating value.

These groups of factors and their mutual relations point out to the necessity of undertaking various activities as regards the state economic policy as well as - on a micro scale - the policy of individual enterprises. These activities should aim towards reducing or eliminating the existing e-technological gap in the economy and e-organisational gap in 
enterprises. It follows that the reception of advanced e-business solutions should be perceived in a larger context of contemporary world economic trends and in the context of global tendencies concerning the transfer of new management ideas, new models of conducting business, and new forms of enterprise organisation.

\section{CHARACTERISTICS OF THE MODEL}

The e-business reception model (EBRM) describes coincidences between the level of reception of advanced e-business solutions and a subjective level of enterprise readiness for executing e-business solutions and a subjective perception of the adequacy of e-business solutions employed for current business tasks. This model also indicates basic determinants of perceived usefulness and perceived ease of reception of advanced e-business solutions in the enterprise, their attributes and interdependencies.

Construction-wise, the EBRM rests on a synergic compilation and extension of three theoretical approaches developed in literature, namely:

- Net Readiness strategies (NR) [17], [20], [31], [44],

- Technology Acceptance Model (TAM) [5], [10], [11], [25], [30], [37], [38], [40], [45], and

- Task-Technology Fit model (TTF) [7], [15], [22], [26].

Apparently, the basic elements of these three theoretical models are closely interrelated.

The activity of the enterprise in new economy is shaped by a number of exogenic and endogenic factors. Some of these factors determine its readiness to operate under the conditions of new economy, and indicating their usefulness in specific conditions and the scope of work required to implement internal changes in the area of the strategy of operations, organisational structure, management system or technical solutions. It can be safely assumed that once Net Readiness procedures are in place, it will be possible to determine all relevant determinants.

Enterprise readiness to implement new solutions also encompasses the effects of other factors which determine the extent to which the enterprise finds such changes attractive and which allow the enterprise to perceive the usefulness of these changes in its ongoing and future activity. These factors can be identified and analysed thanks to the application of the Technology Acceptance Model (TAM) and the Task-Technology Fit Model (TTF). Once all factors are identified, it becomes clear that they are closely interrelated, and it is precisely the EBRM that reflects these interrelations. The EBRM has the following functionalities:
- it supplements Net Readiness strategies, as resulting from the TAM, to include the analysis of external factors which determine the current readiness of the enterprise to use e-business solutions and identifies the effects of NR strategies that relate to individual factors and to the synergy thereof on perceived usefulness and perceived ease of reception of advanced ebusiness solutions (i.e. the core elements of the TAM),

- it links the level of technological acceptance, depending on the identified enterprise Net Readiness level, with the perceived suitability of these technologies to the tasks for which they have been implemented,

- it helps determine the level of reception of advanced e-business solutions, which takes into account the readiness of the enterprise to compete in an e-business environment, the interest of the enterprise to implement new solutions and the perceived usefulness of the new solutions to further the goals of the enterprise.

The implementation of the EBRM in the enterprise helps determine the progress made by the enterprise in the area of e-business and the possible level of reception of advanced e-business solutions with respect to the type and degree of advancement of its business tasks. The EBRM model could be used to find the answer for the research questions as follows:

- what is the actual level of readiness of an enterprise for implementing the IS/IT solutions in its main business,

- what is the actual level and application area of the information technology in an enterprise,

- what is the level of task - information technology fit (TITF) in an enterprise,

- and what is in result the actual level of e-business reception by an enterprise.

The research hypothesis shown in the next part of the paper are well connected with those research questions.

\section{EBRM COMPONENTS AND STRUCTURE}

\section{Level of detail in EBRM}

The EBRM can be presented and analysed on three levels of detail. On the conception level the model reproduces dependencies between the three basic theoretical approaches, i.e. NR, TAM and TTF (Figure 1).

\section{<insert Figure 1 here >}


The exploration level indicates dependencies between the basic elements of the said theoretical approaches, while the operational level describes the dependencies between individual features and factors which determine the basic elements of each theoretical approach.

Since the conception level outlines the main tenets of the EBRM, the remaining part of the article focuses on the other two levels of detail.

\section{EBRM exploration level}

As it has already been mentioned, the EBRM comprises three interweaving spheres characterised by Net Readiness factors, TAM, and TTF. The synergy effect comes from the net of correlations among these factors, as shown in Fig. 2.

\section{<insert Figure 2 here $>$}

Since the enterprise that operate in a given country do so under relatively homogenous conditions and external factors, the analyses presented below refer mainly to endogenic factors which determine individual characteristics and development potential of such enterprises.

Elements of NR such as leadership, competences, infrastructure and management are strictly connected with the basic tenets of the TAM, i.e. perceived usefulness and perceived ease of reception. A detailed review of NR and TAM components suggests that the perceived use of advanced ebusiness solutions, as shown in the TAM, depends on the simultaneous effect of two tenets of NR methodology, i.e. enterprise leadership in this area and its e-business competencies.

Leadership in the area of advanced e-business solutions is, in turn, characterised by the following features:

- knowledge of e-conomy,

- activities undertaken within the enterprise in the area of integrating enterprise business strategy with the measures undertaken in the area of ebusiness,

- accessibility of information within the enterprise,

- focus on developing a strategic value in the enterprise by capitalising on e-business solutions implemented.

Enterprise competencies are, in turn, analysed in terms of:

- the knowledge and experience of the enterprise in the area of e-business solutions,

- flexibility of the enterprise in establishing and maintaining contacts with the outside world,
- activities undertaken in the area of e-business solutions employed in the enterprise.

The perceived ease of reception, on the other hand, is strictly correlated with the other two main tenets of NR, i.e. IT infrastructure (e-business technology) and e-business management. E-business technology, combined with an adequate management system, leads to the establishment of an effective initiative support system that make up the bulk of perceived usefulness. In the area of technology, the following aspects are relevant:

- a properly selected IT infrastructure,

- flexibility of its solutions,

- standardization and unification of its components, and

- the general level of technological advancement of the enterprise.

Individual elements of the infrastructure provide basic tools with which to manage the enterprise and, consequently, allow effective management of advanced e-business solution implementation. In this case the management system can be described by the following features:

- organisational standards of implementing ebusiness solutions,

- development of a set of indicators used to assess the efficacy of activities undertaken in an explicit manner,

- implementation of adequate motivational systems,

- detailed description of the scope of competences and responsibilities of the persons involved in the implementation process.

The final shape of the EBRM also requires the consideration of the effects (on net readiness and technology acceptance related processes) of the adequacy of selection of implemented (or scheduled for implementation) solutions with respect to the ongoing processes of production or service rendering. Factors which characterise the TTF model refer primarily to e-business solutions employed in practice to support the cooperation of the enterprise with the business environment. These are mainly solutions based on available organisational and technological resources which are used in value generation processes, in the supply chain, and in marketing, production and distribution processes (e.g. Electronic Data Interchange systems - EDI, electronic Supply Chain Management - e-SCM, epayments, etc.).

\section{EBRM operational level}

The operational level of the EBRM (Fig. 3) allows for the practical application of the model in the enterprise. 


\section{<insert Figure 3 here $>$}

Such an analysis requires the consideration of the effects of various components of the model. Subjected to quantification, these features can help determine the level of e-business reception in the enterprise. Overall, the EBRM is based on the analysis of 99 features which draw on the tenets of Net Readiness research methods as well as TAM and TTF models. These features cover 5 major elements of the model classified into 16 respective areas. These areas, in turn, describe the current operations of the enterprise under analysis, its factual net readiness, the level of technological acceptance and the adequacy of the technologies employed to executed tasks; consequently, they reflect the current e-business reception level. On this basis and by means of the path analysis, one can determine the extent of the influence of individual features and factors on the level of reception.

In conclusion, the EBRM features help determine:

- the perceived usefulness of e-business, seen from the point of view of leadership in e-business and e-business competencies of the organisation; the perceived usefulness of e-business is a source of information on the potential interest of the enterprise in e-business solutions and on the level of readiness of individual members of the organisation treated as a system for e-business reception,

- the perceived ease of e-business reception, manifesting clearly the relations with the infrastructure (specifically Information Systems/Information Technology - IS/IT) and the e-business management system employed by the enterprise; the perceived ease of e-business reception provides information on the organisational and infrastructural capacity as well as potential barriers that are or may be present in e-business reception processes in the enterprise,

- the reception intent which reflects the activity of the top management in e-business reception processes in general and specifically in developing and implementing organisation solutions in the enterprise which provide inspiration of and support to various e-business initiatives,

- the reception level which reflects the current utilisation of e-business in the enterprise. The reception level provides an insight into the way in which e-business conceptions and initiatives ate translated into real e-business activities undertaken under specific conditions; the analysis of the reception level in the enterprise helps, among other things, to interpret the effects of e- business solutions adopted on the finances and organisation of the enterprise and to determine their effects on customer behaviour and enterprise cooperation schemes,

- components of the TTF model which determine the technological aspects of e-business reception processes; once a relevant analysis is made, it is possible for the enterprise to assess the effects of the tasks performed on the selection of IS/IT technologies and solutions adopted.

Table 1 presents the classification of EBRM factors and the number of corresponding features as shown in individual areas under research.

\section{<insert Table 1 here $>$}

\section{SCIENTIFIC HYPOTHESES IN THE EBRM}

The structure of the EBRM is based on the classification of scientific hypotheses which refer to the three levels of detail. Main hypotheses are specified on the conception level; auxiliary hypotheses fall under the terms of reference of the exploration level while supplementary hypotheses or sub-hypotheses are formulated on the operational level. Table 2 lists the symbols of hypotheses employed to verify the EBRM.

\section{<insert Table 2 here $>$}

The hypotheses are causative in nature, and their aim is to verify the adequacy of the main idea of the model, the existence of interrelations among the three methodological approaches (i.e. elements of the model), and the legitimacy of the adopted structure of the model. The main hypotheses read as follows:

H.I: There is a positive correlation between the level of reception of advanced e-business solutions and the Net Readiness level.

H.II: There is a positive correlation between the level of reception of advanced e-business solutions and the perceived adequacy of these solutions to production tasks executed.

The main hypotheses were broken down on the exploration level into three auxiliary hypotheses (H1H3). On the operational level, these hypotheses were subsequently used to formulate 11 scientific subhypotheses (H1A-H3C). Figure 2 shows relations between individual elements of the EBRM and the hypotheses adopted.

The rationale behind formulating auxiliary hypotheses was to break down each theoretical approach applied in the EBRM (i.e. NR, TAM, and TTF) into functional elements (areas of relationships) and to demonstrate the existence of positive correlations among them. The sub-hypotheses 
established on the operational level are used exclusively for the purposes of in-depth analyses and empirical verification of individual relations of the elements in question in individual theoretical approaches.

The first auxiliary hypothesis identifies relations between the NR level and perceived ease of reception of advanced e-business solutions in the enterprise:

Hypothesis H1: the Net Readiness level has a positive effect on e-business reception in the enterprise.

H1 hypothesis comprises four operational subhypotheses. They refer to individual strategic factors of advanced e-business reception and help determine the effect of e-business advancement level on ebusiness reception, i.e.:

H1A: There is a positive correlation between leadership in the applications of advanced e-business solutions and the perceived usefulness of these solutions in the enterprise.

H1B: There is a positive correlation between the competencies in applying advanced e-business solutions in the enterprise with the perceived usefulness of these solutions.

H1C: There is a positive correlation between the level of implementation and use of IT infrastructure to support advanced e-business solutions and the perceived ease of reception of advanced e-business solutions.

H1D: There is a positive correlation between the effective advanced e-business solutions management system and the perceived ease of reception of these solutions in the enterprise.

The second auxiliary hypothesis indicates a correlation between the current level of reception of advanced e-business solutions in the enterprise and the interest of the enterprise in relevant reception processes:

Hypothesis H2: The TAM specifies intentions and current readiness of the enterprise to receive advanced e-business solutions.

This hypothesis comprises four sub-hypotheses used to verify the effect of endogenic environmental factors on e-business reception, i.e.:

H2A: There is a positive correlation between the usefulness of advanced e-business solutions and the intended reception in the ongoing activity of the enterprise.

H2B: There is a positive correlation between the perceived usefulness of advanced e-business solutions and the current level of reception of advanced e-business solutions in the enterprise.

H2C: There is a positive correlation between the perceived ease of reception of advanced e-business solutions and intended reception of these solutions in the enterprise.
H2D: There is a positive correlation between the intended reception of advanced e-business solutions and the current level of reception of these solutions in the enterprise.

The third auxiliary hypothesis combines the issues relating to the acceptance of e-business with those relating to the adequacy (compatibility) of advanced e-business solutions employed to carry out business tasks in the enterprise:

Hypothesis H3: The TTF model specifies the intentions and current level of readiness of the enterprise to receive advanced e-business solutions, as seen from the point of view of the compatibility of these solutions with the production or service-related tasks currently underway.

Hypothesis H3 comprises three sub-hypotheses which refer to the process-related endogenic factors on the level of e-business reception. Combined with the environmental factors (H2), these sub-hypotheses have been used to analyse the relations that occur between the types of business tasks executed and the selection of technologies employed primarily to support the same, i.e.:

H3A: There is a positive correlation between the adequacy of advanced e-business solutions employed to execute production tasks and the perceived usefulness of advanced e-business solutions.

H3B: There is a positive correlation between the level of adequacy of advanced e-business solutions employed to execute production tasks and the perceived ease of reception of these solutions in the enterprise.

H3C: There is a positive correlation between the level of adequacy of advanced e-business solutions employed to execute production tasks and the intended reception of the same in the enterprise.

The correlations determined among various elements of the EBRM on the operational level (the highest level of detail) will induce cause-and-effect relations among the analysed elements of the model on the exploration level, and, in turn, will constitute a premise for the positive verification of the EBRM on the conception model. At present analyses relating to the verification of the EBRM and the data collected while surveying Polish enterprises (approx. 70 entities) are well underway. The results of these studies are scheduled for publication at the end of 2008. At the moment a new paper of the author is going to be finished (see [31]). There were presented the results obtained from the analysis of variance (ANOVA) and from Tukey's multiple range test, performed with Statgraphics software. Further research studies, currently conducted by the author of this article, are aimed to expand the concept of the EBRM model, with a view to incorporating the regression analysis. A positive verification of the 
model will also facilitate international studies planned for 2009.

\section{CONCLUSIONS}

Implementation of e-business solutions in the enterprise is of vital importance in view of individual economies operating on the markets dominated by global competition. Changes in these markets, new ways in which technological, social, cultural, economic, political, and legal factors are at play in the new economy constitute ever-growing threats to traditional organisational models and traditional forms of conducting business activity. In addition to the steady pressure on adaptation, restructuring and reengineering in learning enterprises, these threats can be mitigated by the capacity to generate an added value with the application of new technologies and new forms of enterprise organisation based on IS/IT solutions. Knowledge in this area allows one to make long-term decisions which translate into an improved competitive position on the level of individual enterprises and - indirectly - on the level of the economy as a whole.

At the same time, this area of research demonstrates considerable flexibility and openness. The directions and range of potential applications of the presented EBRM are determined by the pace of development of a given economy as well as by the sustainability of its enterprises in the new economy environment characterised by permanent change. It seems that the EBRM can be put to good use in such areas as the implementation of high-tech solutions, elearning solutions characteristic of the information society or in reorganising all spheres of activity of enterprises or other organisations which face the problem of implementing new solutions and farreaching changes to their existing structures and business strategies.

Suggested areas for further research could be concentrated on i.e.: the use of construction of the EBRM in evaluation of AMT (Advanced Manufacturing Technology) reception, the reception of e-learning technologies by different groups of users, or reception of different technologies or organisational solutions that are characteristic of new economy era.

\section{REFERENCES}

1. Adesola, S., Baines, T. (2005). Developing and evaluating a methodology for business process improvement. Business Process Management Journal, 11(1), pp. 37-46.

2. APEC. (2000). E-commerce readiness assessment guide. A Partnership of the Business
Community With APEC Economies, APEC Readiness Initiative Two Thousand, available: www.ecommerce.gov/apec.

3. Australian Bureau of Statistics. (2004). Knowledge-based Economy and Society, AsiaPacific ICT Technical Meeting, Wellington, New Zealand, $30^{\text {th }}$ November- $2^{\text {nd }}$ December.

4. Australian Bureau of Statistics. (2004a). Measuring a Knowledge-Based Economy and Society. An Australian Framework, Asia-Pacific ICT Technical Meeting, Wellington, New Zealand, $30^{\text {th }}$ November- $2^{\text {nd }}$ December, Art. No. 1375.0, pp. 20-28.

5. Baron, S., Patterson, A., Harris, K. (2006). Beyond technology acceptance: understanding consumer practice. International Journal of Service Industry Management. 17(2), pp. 111135.

6. Becker, F. (2000). Integrated portfolio strategies for dynamic organizations. Facilities, 18(10/11/12), pp. 411-420.

7. Burgess, T.F., Shaw, N.E., de Mattos, C. (2005). Organisational self-assessment and the adoption of managerial innovations. International Journal of Productivity and Performance Management. 54(2), pp. 98-112.

8. Dahan, E., Hauser, J.R. (2001). The Virtual Customer: Communication, Conceptualization, and Computation. MIT Papers, 104, September, pp. 1-3.

9. Davidson, B. (2004). Breakthrough. John Wiley \& Sons, Inc.

10. Davis, F.D. (1989). Perceived usefulness, perceived ease of use, and user acceptance of information technology. Management Information Systems Quarterly. 13, pp. 319-339.

11. Del Aguila-Obra, A.R., Padilla-Melendez, A. (2006). Organizational factors affecting Internet technology adoption. Internet Research. 16(1), pp. 94-110.

12. Dutta, S. (2003). The importance of organizational leadership for creating technology excellence, [in:] The Global Information Technology Report 2001-2002: Readiness for the Networked World. Center for International Development at Harvard University, Cambridge, MA, USA.

13. Eggleston, K., Jensen, R., Zeckhauser, R. (2003). Information and Communication Technologies, Markets, and Economic Development, [in:] The Global Information Technology Report 20012002: Readiness for the Networked World. Center for International Development at Harvard University, Cambridge, MA, USA.

14. Garfield, E. (1955). Citation Indexes for Science: A New Dimension in Documentation through 
Association of Ideas. Science, 122(3159), pp. 108-111.

15. Goodhue, D.L., Thompson, R.L. (1995). Tasktechnology fit and individual performance. Management Information Systems Quarterly. 19(2), pp. 213-236.

16. Gottschalk, P. (2006). Knowledge Management Systems: Value Shop Creation. Idea Group Publishing, Hershey, PA.

17. Hartman, A., Sifonis, J., Kador, J. (2000). Net Ready - Strategies for Success in the E-conomy. McGraw-Hill Companies.

18. Harvard University. (2003). The Global Information Technology Report 2001-2002: Readiness for the Networked World. Center for International Development at Harvard University, Cambridge, MA, USA.

19. Jacobs, C.D., Heracleous, L.T. (2005). Answers for questions to come: reflective dialogue as an enabler of strategic innovation. Journal of Organizational Change Management. 18(4), pp. 338-352.

20. Jutla, D., Bodorik, P., Dhaliwal, J. (2002). Supporting the e-business readiness of small and medium-sized enterprises: approaches and metrics. Internet Research. 12(2), pp. 139-164.

21. Kidd, J., Richter, F.J., Li, X. (2003). Learning and trust in supply chain management. Management Decision. 41(7), pp. 603-612.

22. Klopping, I.M., McKinney, E. (2004). Extending the Technology Acceptance Model and the TaskTechnology Fit Model to Consumer ECommerce. Information Technology, Learning, and Performance Journal. 22(1), pp. 35-48.

23. Koutsoukis, N.S., Dominguez-Ballesteros, B., Lucas, C.A., Mitra, G. (2000). A prototype decision support system for strategic planning under uncertainty. International Journal of Physical Distribution \& Logistics Management. 30(7/8), pp. 640-660.

24. Littler, D., Knights, D., Coombs, R., Bloomfield, B.P. (2000). Information Technology and Organizations. Strategies, Networks, and Integration. Oxford University Press.

25. Lu, H.-P., Hsu, Ch.-L., Hsu, H.-Y. (2005). An empirical study of the effect of perceived risk upon intention to use online applications. Information Management \& Computer Security. 13(2), pp. 106-120.

26. Lu, J., Yu, Ch.-S., Liu, Ch., Yao, J.E. (2003). Technology acceptance model for wireless Internet. Internet Research. 13(3), pp. 206-222.

27. Machlup, F. (1962). The Production and Distribution of Knowledge in The United States. Princeton University Press, Princeton, New Jersey.
28. McNurlin, B., Sprague, R.H. (2000). Information Systems Management in Practice. Prentice Hall, 5th ed., New Jersey.

29. Nanclares, N.H., Lopez, F.L. (2000). The so called new economy and the ICT: concept and measurement. London School of Economics Seminar of the Global Consequences of the Information Technology. Madrid, March, $20^{\text {th }}$ $24^{\text {th }}$.

30. Ndubisi, N.O., Jantan, M. (2003). Evaluating IS usage in Malaysian small and medium-sized firms using the technology acceptance model. Logistics Information Management. 16(6), pp. 440-450.

31. Pastuszak, Z. (2008). E-Business Reception in Service and Manufacturing Companies. Proceedings of MIC 2008 - Management International Conference. Intercultural Dialogue and Management, University of Primorska, University Centre for Euro-Mediterranean Studies (EMUNI), European Institute of the Mediterranean (IEMed), Barcelona, Spain, November, $26^{\text {th }}-29^{\text {th }}$ (forthcoming).

32. Pastuszak, Z. (2007). E-Technological and eOrganisational Gap in Polish Economy, Proceedings of MIC 2007 - Management International Conference. Managing Global Transitions: Globalisation - Localisation Regionalisation, University of Primorska, Portorož, Slovenia, November, $20^{\text {th }}-24^{\text {th }}$.

33. Quah, D. (2001). Technology dissemination and economic growth: Some lesson for the New Economy. Trade and Industrial Policy Strategies, Annual Forum. Misty Hills, Muldersdrift, 10-12 September, pp. 1-35.

34. Romano, A., Passiante, G., Elia, V. (2001). New sources of clustering in the digital economy. Journal of Small Business and Enterprise Development. 8(1), pp. 19-27.

35. Schultz, T.W. (1961). Investment in Human Capital. The American Economic Review. 1(2), pp. 1-17.

36. Simatupang, T.M., Wright, A.C., Sridharan, R. (2002). The knowledge of coordination for supply chain integration. Business Process Management Journal. 8(3), pp. 289-308.

37. Singh, N., Fassott, G., Chao, M.C.H., Hoffmann, J.A. (2006). Understanding international web site usage. A cross-national study of German, Brazilian, and Taiwanese online consumers. International Marketing Review. 23(1), pp. 8397.

38. Snowden, S., Spafford, J., Michaelides, R., Hopkins, J. (2006). Technology acceptance and $\mathrm{m}$-commerce in an operational environment. 
Journal of Enterprise Information Management. 19(5), pp. 525-539.

39. Stabell, C.B., Fjeldstand, Ø.D. (1998). Configuring value for competitive advantage: On chains, shops, and networks. Strategic Management Journal. 19, pp. 413-437.

40. The Economist. (2007). The 2007 e-readiness rankings, Raising the bar. A white paper from the Economist Intelligence Unit, The Economist Intelligence Unit Limited \& IBM Institute for Business Value, London-New York-Hong Kong.

41. The Economist. (2005). The 2005 e-readiness rankings. The Economist Intelligence Unit Limited \& IBM Institute for Business Value, London-New York-Hong Kong.

42. World Bank. (2006). Knowledge Assessment Methodology. Available: http://web.worldbank.org.

43. World Economic Forum. (2005). The Global Information Technology Report 2003-2004: Towards an Equitable Information Society. World Economic Forum, Oxford University Press, Geneva, March.

44. Wu, Ch. (2004). A readiness model for adopting Web services. Journal of Enterprise Information Management. 17(5), pp. 361-371.

45. Xu, J., Quaddus, M. (2005). Exploring the perceptions of knowledge management systems. Journal of Management Development. 24(4), pp. 320-334. 


\section{TABLES AND FIGURES}

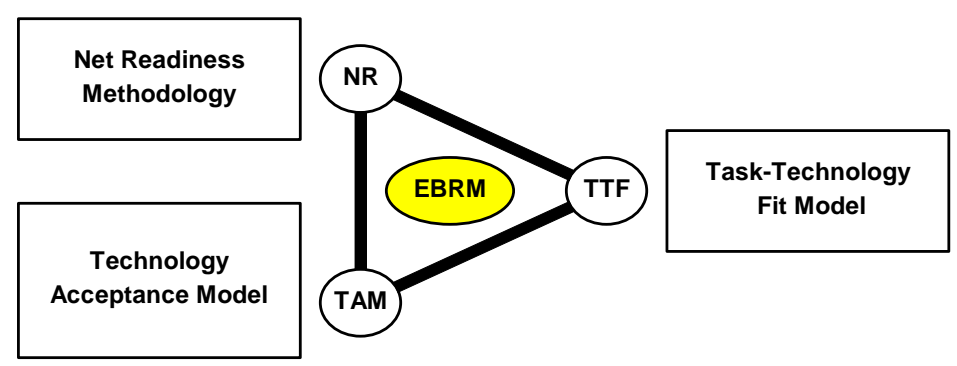

Figure 1. EBRM conception level

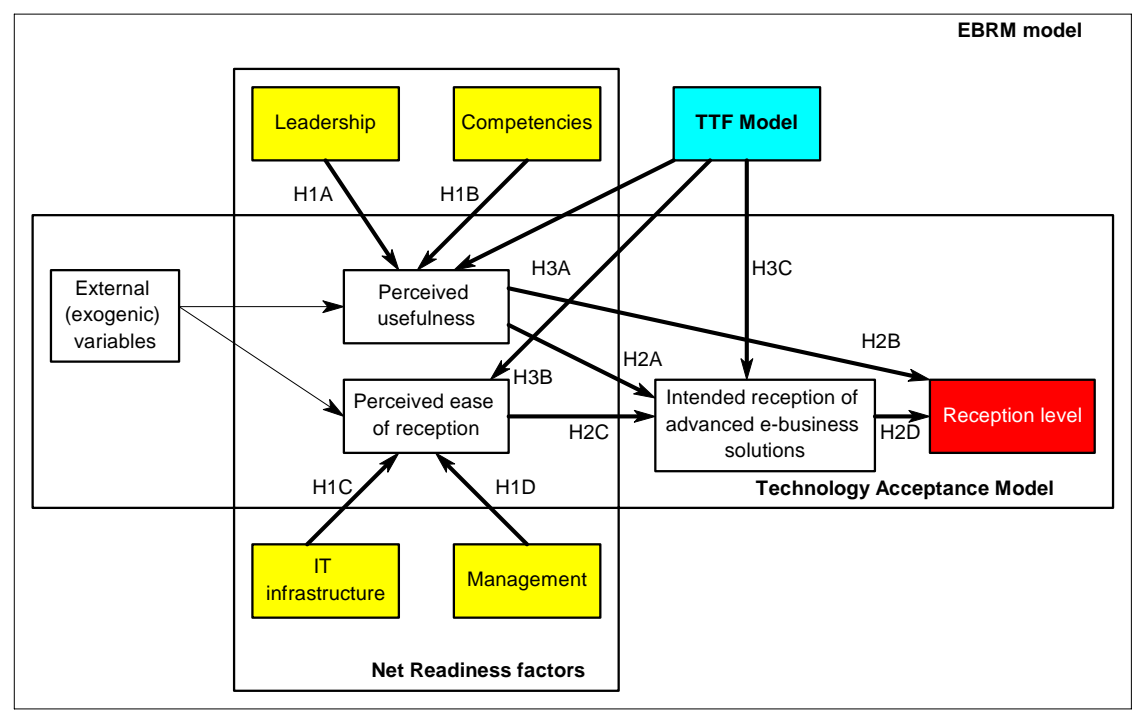

Figure 2. EBMR exploration level and scientific hypotheses 


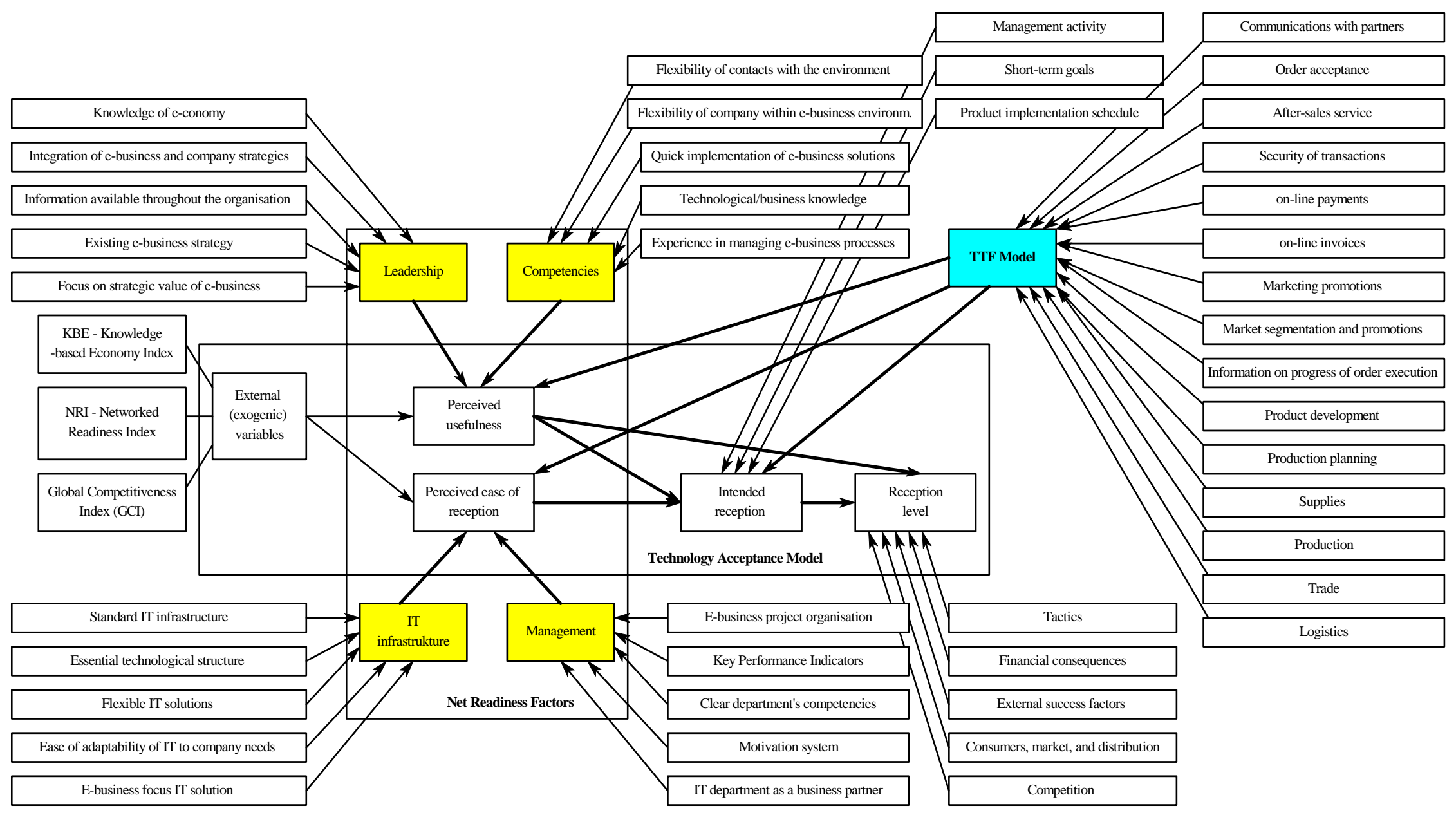

Figure 3. EBRM operational level 
Table. 1. Classification of EBRM factors

\begin{tabular}{|c|l|c|c|}
\hline No. & EBRM components & Coding & Number of areas and analysed features \\
\hline $\mathbf{1}$ & Perceived usefulness & $\mathbf{P U}$ & $\mathbf{2}$ areas (10 features altogether) \\
\hline 1.1 & Leadership & $\mathrm{P}$ & 5 \\
\hline 1.2 & Competencies & $\mathrm{K}$ & 5 \\
\hline $\mathbf{2}$ & Perceived ease of reception & $\mathbf{P L U}$ & $\mathbf{2}$ areas (10 features altogether) \\
\hline 2.1 & IS/IT infrastructure & $\mathrm{I}$ & 5 \\
\hline 2.2 & Management & $\mathrm{Z}$ & 5 \\
\hline $\mathbf{3}$ & Intended reception & IR & $\mathbf{3}$ areas (14 features altogether) \\
\hline 3.1 & Activity of enterprise management & - & 2 \\
\hline 3.2 & Short-term goals & - & 4 \\
\hline 3.3 & Implementation of products and services schedule & - & 8 \\
\hline $\mathbf{4}$ & Reception level (current use of e-business) & $\mathbf{R E C}$ & $\mathbf{5}$ areas (35 features altogether) \\
\hline 4.1 & Tactics & - & 7 \\
\hline 4.2 & Financial consequences & - & 6 \\
\hline 4.3 & External success factors & - & 3 \\
\hline 4.4 & Consumers, market, distribution channels & - & 11 \\
\hline 4.5 & Competition & - & 8 \\
\hline $\mathbf{5}$ & Task-Technology Fit $-\mathbf{T T F}$ & $\mathbf{T T F}$ & $\mathbf{4}$ areas (30 features altogether) \\
\hline 5.1 & Internet link technology & - & 7 \\
\hline 5.2 & Active use of enterprise website & - & 3 \\
\hline 5.3 & Scope of use of enterprise website & - & 14 \\
\hline 5.4 & Scope of use of advanced IT systems in the enterprise & - & 6 \\
\hline & TOTAL & - & $\mathbf{1 6}$ areas (99 features altogether) \\
\hline
\end{tabular}

Source: Author's own studies.

Table 2. Hypotheses in the EBRM

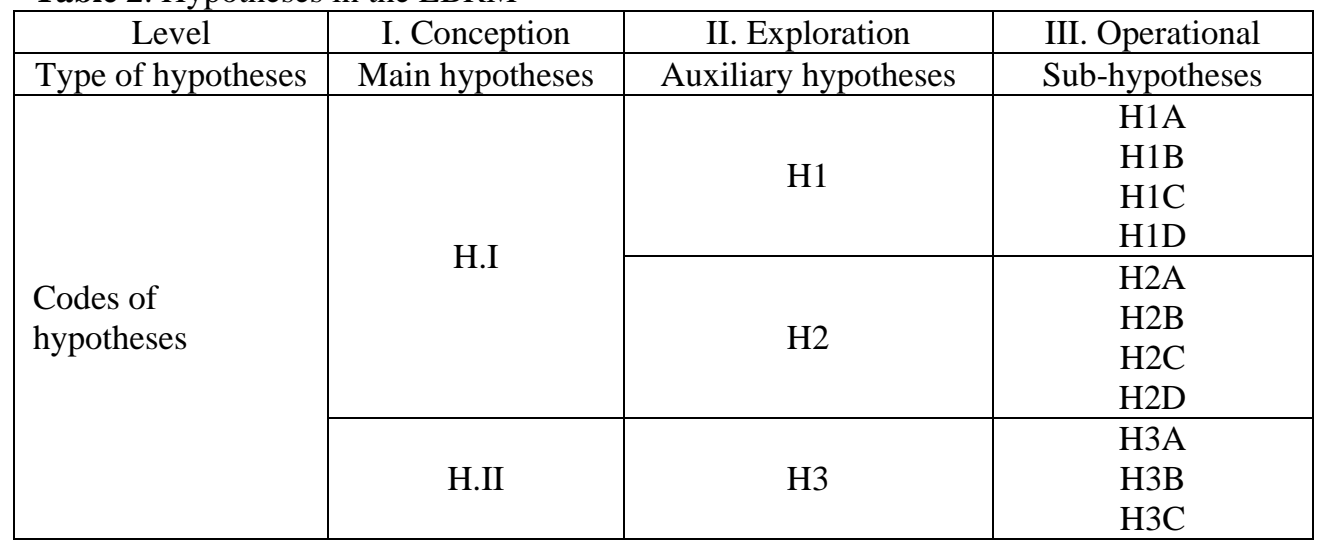

